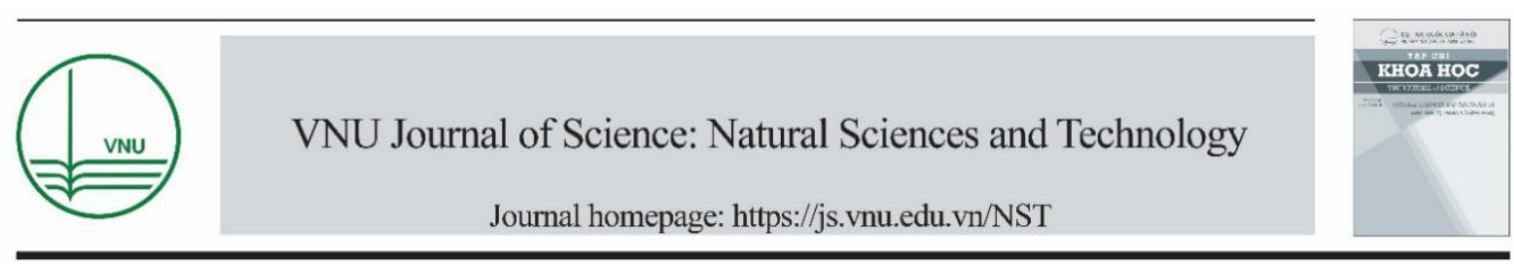

\title{
Original Article \\ Seasonal Variability in the Genus-Family Structure of Free-Living Nematode Communities in Organic Shrimp Farming Ponds, Ca Mau Province
}

\author{
Tran Thanh Thai ${ }^{1, *}$, Ngo Xuan Quang ${ }^{1,2}$ \\ ${ }^{1}$ Institute of Tropical Biology, Vietnam Academy of Science and Technology, \\ 85 Tran Quoc Toan Street, District 3, Ho Chi Minh City, Vietnam \\ ${ }^{2}$ Graduate University of Science and Technology, Vietnam Academy of Science and Technology, \\ 18 Hoang Quoc Viet, Cau Giay, Hanoi, Vietnam
}

Received 13 February 2019

Revised 15 March 2019; Accepted 15 March 2019

\begin{abstract}
This study determined the seasonal variability of free-living nematode communities structure (genus/family level) in organic shrimp farms ponds in Tam Giang commune, Nam Can district, Ca Mau province. Based on the result of SIMPER analysis, the average similarity in nematode communities at genus level was low with $30.75 \%$ and $30.81 \%$ (in dry and rainy season, respectively). However, the average dissimilarity between seasons was considerably high with 71.75\%. Terschellingia, Daptonema, and Parodontophora were main genera contributing to similarity/dissimilarity between seasons. At the family level, results of SIMPER analysis showed that the average similarity was low with $37.12 \%$ and $39.02 \%$ (dry and rainy, respectively). Additionally, the average dissimilarity between dry and rainy season was reasonably high with 64.06\%. Specifically, four families such as Linhomoeidae, Xyalidae, Axonolaimidae, and Chromadoridae were the main families contributing to similarity/dissimilarity between seasons. Differences in sediment environmental characteristics between dry and rainy season are the reason for dissimilarity in the nematode communities structure. The high abundance of genus Terschellingia, Daptonema, Parodontophora may be indicative of organic enrichment conditions in shrimp pond sediment in both seasons. Nematodes with their rapid adaptation to changing environments can be used as a potential tool for bio-indicator.
\end{abstract}

Keywords: Bio-indicator, Ca Mau province, nematode communities, organic shrimp farms ponds, simper analysis.

\section{Introduction}

Southern Vietnam has a tropical monsoon climate which is described with two main seasons: dry season and rainy season. The dry season lasts from November to April, while the period from May to October is rainy season [1]. Nematodes are roundworms of the phylum Nematoda, as most are highly sensitive to natural and anthropogenic disturbances [2]. Thus, the

\footnotetext{
* Corresponding author.

Email address: thanhthai.bentrect@gmail.com

https://doi.org/10.25073/2588-1140/vnunst.4864
} 
complicated natural conditions and seasonal fluctuations in Southern Vietnam have had an enormous impact on nematode communities structure [3]. In the last few years, the effects of a seasonal factor on nematode communities have been studied at different places over the world. Heip et al. (1985) have warned that the seasonal variability on the species composition of nematodes could be very different from site to site and depending on local environmental conditions [4]. The study by Hodda and Nicholas (1986) in littoral nematodes from the Hunter estuary, New South Wales, Australia was notable that large fluctuations in the total nematode density at the various sites throughout the year [5]. Another study of Alongi (1987) in five Australian estuaries found that the nematode densities were not significantly different among estuaries, but differed seasonally (summer greater than winter) [6]. Tudorancea and Zullini (1989) studied nematode abundances in the tropical regions, reported that the abundance was highest at the end of dry season and the beginning of a small rainy season [7]. The production of meiofaunal communities in an Australia estuary during four seasons showed that the proportion of adult males and juveniles in the population and their mean size changed by season factor described by Hodda and Nicholas (1990) [8]. Beier and Traunspurger (2003) studied nematode communities in sub-mountain carbonate stream (Southwest Germany) and found that the total of nematode abundances was low during summer, autumn and winter and reached a maximum density in spring. The density of deposit- and suction-feeders similar to the variation in total nematode density was low during summer, autumn, winter, and showed the highest values in spring [9]. Similar results have been reported by Hourston et al. (2009) in Swan river estuary (West coast of Australia), nematode densities were also generally highest in spring, due to increases in the abundance of natural food (microphytobenthos) [10].

The unplanned expansion in shrimp farming in the Mekong Delta region has also had negative effects on the environment and caused devastating damage to mangrove forests [11]. A model of organic shrimp farms is developed to combat this problem. The model integrates shrimp aquaculture with mangrove protection, and thus it's sustainable development of shrimp farming in the coastal areas [12]. Nematode communities are a primary food source for the diet of shrimps [13, 14]. Thus, several studies have been performed for the ecology of nematodes in organic shrimp farm pond's sediments. Free-living nematode communities in the Tam Giang's organic shrimp farms ponds, Nam Can district, Ca Mau province were expressed by high density and diversity [11]. This characteristic of free-living nematode communities in organic shrimp farming ponds might provide a suitable natural food source for shrimps and enrich the benthic food web [15]. Furthermore, Tran et al. (2018) conducted a correlation analysis between some dominant nematode genera with the main environmental variables. Results showed that the environmental condition in dry season was separated from other seasons, salinity was the main factor responsible for the differences found between dry and other seasons. Additionally, salinity was a main environmental variable in the dry season, whereas in the trans and wet seasons were governed by $\mathrm{Fe}^{2+}, \mathrm{Fe}^{3+}$, TN, TOC, DO, pH, and depth. These environmental characteristics almost completely governed the dominant genera such as Desmodora, Sabatieria, Terschellingia, Dichromadora, Pomponema, Halalaimus, Ptycholaimellus, and Sphaerotheristus [11].

Due to complicated natural conditions in an organic shrimp farming ponds related to seasonal fluctuations, it is important to get an idea on the seasonal variability of the nematode communities structure between dry and rainy season. Therefore, our aim is to (i) identify average similarities and dissimilarities in nematode communities between dry and rainy season (at genus and family level), (ii) determine genera/families responsible for similarities and dissimilarities in both seasons. 


\section{Materials and Methods}

\subsection{Study area and sampling}

The present study was carried out in March (dry season) and November (rainy season) of 2015 at eight different organic shrimp ponds distributed in Tam Giang commune, Nam Can district, Ca Mau province. Study area and sampling activities have been described in detail by Tran et al. (2018) [11].

\subsection{Data analysis}

An Analysis of similarities (ANOSIM) was applied for comparing the nematode communities structure (genus/family level) between dry and rainy season. Additionally, the SIMPER analysis (SIMilarity PERcentages) was used for identifying (i) average similarity and dissimilarity between dry and rainy season (at genus and family level), and (ii) the genera and families responsible for similarity and dissimilarity between both seasons. The ANOSIM and SIMPER were performed using PRIMER v6.1.6 [16].

\section{Results and Discussion}

\subsection{Genera responsible for similarity and} dissimilarity between dry and rainy season

Overall, the nematode communities in eight organic shrimp ponds, Tam Giang commune, Nam Can district, Ca Mau province consisted of 75 genera belonging to 24 families, 7 orders, in dry season. However, in rainy season the number of collected genera was relatively low, with 57 genera, 26 families, and 9 orders [11].

In dry season, results of the SIMPER analysis confirmed that the average similarity in nematode communities was low with $30.75 \%$. Five genera such asTerschellingia

Daptonema, Parodontophora, Ptycholaimellus, Pseudolella, and Dichromadora were main genera contributing to similarities in dry season. More specifically, genus Terschellingia was the one with the most contribution (with $33.39 \%$ of total contribution) followed by Daptonema (18.07\%),

Parodontophora (9.93\%), Ptycholaimellus (9.45\%), Pseudolella (5.84\%), and Dichromadora $(3.66 \%)$. In rainy season, the average similarity in nematode communities was also low with $30.81 \%$. Terschellingia, Daptonema, and Parodontophora were also known as the most contribution genera (with $30.61 \%$, 20.79\%, and $11.72 \%$, respectively). The sub- contribution genera were Pseudolella and Dichromadora $(7.40 \%$ and $7.16 \%$, respectively). Genus Ptycholaimellus had also contributed with a lower proportion $(1.93 \%)$ than that in dry season. In both seasons, genera Sabatieria,

Gomphionema, Halalaimus, Desmodora, Sphaerotheristus, Hopperia, Metadesmolaimus, and Eumorpholaimus had also contributed with their percentages ranged from $1.09 \%$ to $4.13 \%$. The percentages of the remaining genera were lower than $1.00 \%$ of the total contribution (Table $1)$.

Table 1. Average similarities and major nematode genera contributing to the similarity in dry/rainy season. Cut off for low contributions: $95.00 \%$ (Av.Si: Average Similarity; Con: Contribution, Cum: Cumulative)

\begin{tabular}{llllllll}
\hline Dry (Av.Si: $30.75 \%)$ & \multicolumn{7}{c}{ Rainy (Av.Si: 30.81\%) } \\
\hline Genera & Av.Si & Con & Cum & Genera & Av.Si & Con & Cum \\
Terschellingia & $(\%)$ & $(\%)$ & $(\%)$ & & $(\%)$ & $(\%)$ & $(\%)$ \\
Daptonema & 10.27 & 33.39 & 33.39 & Terschellingia & 9.43 & 30.61 & 30.61 \\
Parodontophora & 5.56 & 18.07 & 51.46 & Daptonema & 6.40 & 20.79 & 51.40 \\
Ptycholaimellus & 3.05 & 9.93 & 61.39 & Parodontophora & 3.61 & 11.72 & 63.11 \\
Pseudolella & 2.91 & 9.45 & 70.84 & Pseudolella & 2.28 & 7.40 & 70.51 \\
Dichromadora & 1.79 & 5.84 & 76.67 & Dichromadora & 2.21 & 7.16 & 77.67 \\
Sabatieria & 1.12 & 3.66 & 80.33 & Gomphionema & 1.27 & 4.13 & 81.8 \\
Gomphionema & 1.01 & 3.28 & 83.61 & Sphaerotheristus & 1.19 & 3.85 & 85.65 \\
\hline
\end{tabular}




\begin{tabular}{llllllll}
\hline Halalaimus & 0.52 & 1.69 & 88.22 & Ptycholaimellus & 0.59 & 1.93 & 90.22 \\
Desmodora & 0.50 & 1.62 & 89.84 & Metadesmolaimus & 0.47 & 1.52 & 91.73 \\
Sphaerotheristus & 0.36 & 1.17 & 91.01 & Eumorpholaimus & 0.43 & 1.40 & 93.13 \\
Hopperia & 0.33 & 1.09 & 92.1 & Desmodora & 0.34 & 1.12 & 94.25 \\
Theristus & 0.27 & 0.86 & 92.96 & Chromadorita & 0.26 & 0.84 & 95.09 \\
Metachromadora & 0.26 & 0.86 & 93.82 & & & & \\
Linhystera & 0.24 & 0.77 & 94.59 & & & & \\
Eumorpholaimus & 0.19 & 0.63 & 95.22 & & & & \\
\hline
\end{tabular}

The SIMPER analysis also showed that the average dissimilarity between seasons was considerably high with $71.75 \%$. Genus Terschellingia served as the key one responsible for the dissimilarity between dry and rainy season (with $18.86 \%$ of total contribution). Additionally, Daptonema, Parodontophora, Pseudolella, Dichromadora, Ptycholaimellus, Gomphionema, and Sphaerotheristus were also known as the sub-contribution genera (with
$13.51 \%, 6.39 \%, 6.35 \%, 5.04 \%, 4.85 \%, 3.34 \%$, and $4.4 .4 \%$, respectively). The contributed percentages of the remaining genera were lower than $2.00 \%$ of the total contribution (Table 2). Furthermore, the results of an ANOSIM analysis confirmed that there were significant differences in nematode communities structure (genus level) between dry and rainy season (Global $\mathrm{R}=0.095$, $\mathrm{p}$-value $=0.007)$.

Table 2. Average dissimilarities and major nematode genera contributing to the dissimilarity between dry and rainy season. Cut off for low contributions: 95.00\% (Av.Dis: Average Dissimilarity; Con: Contribution; Cum: Cumulative)

\begin{tabular}{|c|c|c|c|c|c|c|c|}
\hline \multicolumn{8}{|c|}{ Average dissimilarity: $71.75 \%$} \\
\hline Genera & $\begin{array}{l}\text { Av.Dis } \\
(\%)\end{array}$ & $\begin{array}{l}\text { Con } \\
(\%)\end{array}$ & $\begin{array}{l}\text { Cum } \\
(\%)\end{array}$ & Genera & $\begin{array}{l}\text { Av.Dis } \\
(\%)\end{array}$ & $\begin{array}{l}\text { Con } \\
(\%) \\
\end{array}$ & $\begin{array}{l}\text { Cum } \\
(\%)\end{array}$ \\
\hline Terschellingia & 13.53 & 18.86 & 18.86 & Theristus & 1.02 & 1.42 & 84.13 \\
\hline Daptonema & 9.69 & 13.51 & 32.37 & Marylynnia & 0.85 & 1.19 & 85.31 \\
\hline Parodontophora & 4.59 & 6.39 & 38.76 & Sphaerolaimus & 0.76 & 1.06 & 86.37 \\
\hline Pseudolella & 4.56 & 6.35 & 45.11 & Metachromadora & 0.74 & 1.03 & 87.40 \\
\hline Dichromadora & 3.62 & 5.04 & 50.16 & Pomponema & 0.62 & 0.87 & 88.27 \\
\hline Ptycholaimellus & 3.48 & 4.85 & 55.01 & Hopperia & 0.61 & 0.85 & 89.12 \\
\hline Gomphionema & 3.19 & 4.44 & 59.45 & Halichoanolaimus & 0.56 & 0.79 & 89.91 \\
\hline Sphaerotheristus & 2.39 & 3.34 & 62.79 & Anoplostoma & 0.51 & 0.71 & 90.62 \\
\hline Halalaimus & 2.34 & 3.26 & 66.05 & Viscosia & 0.50 & 0.69 & 91.31 \\
\hline Sabatieria & 2.09 & 2.91 & 68.96 & Trissonchulus & 0.43 & 0.60 & 91.91 \\
\hline Metadesmolaimus & 2.02 & 2.81 & 71.77 & Paraplectonema & 0.39 & 0.55 & 92.45 \\
\hline Desmodora & 1.82 & 2.53 & 74.3 & Monhystera & 0.34 & 0.47 & 92.93 \\
\hline Eumorpholaimus & 1.43 & 1.99 & 76.29 & Aegialoalaimus & 0.32 & 0.45 & 93.38 \\
\hline Eleutherolaimus & 1.19 & 1.65 & 77.95 & Molgolaimus & 0.32 & 0.44 & 93.82 \\
\hline Chromadorita & 1.17 & 1.64 & 79.58 & Subsphaerolaimus & 0.31 & 0.44 & 94.26 \\
\hline Leptolaimus & 1.17 & 1.63 & 81.22 & Microlaimus & 0.30 & 0.42 & 94.67 \\
\hline Linhystera & 1.07 & 1.49 & 82.7 & Antomicron & 0.26 & 0.36 & 95.03 \\
\hline
\end{tabular}




\subsection{Families responsible for similarity and dissimilarity between dry and rainy season}

At the family level, in dry season, results of the SIMPER analysis showed that the average similarity in nematode communities was low with $37.12 \%$. The most contributing families were Linhomoeidae, Xyalidae, Axonolaimidae, and Chromadoridae $(23.43 \%, 20.78 \%, 15.53 \%$, and $12.48 \%$, respectively). Generally, the nematode communities structure at the family level did not fluctuate greatly between dry and rainy season. In rainy season, the average similarity in nematode communities was also low with $39.02 \%$. Xyalidae, Linhomoeidae, Axonolaimidae, and Chromadoridae were also known as the four most contribution families with $26.60 \%, 26.32 \%, 13.67 \%$, and $10.74 \%$, respectively (Table 3).

Table 3. Average similarities and major nematode families contributing to similarity in dry/rainy season. Cut off for low contributions: $95.00 \%$ (Av.Si: Average Similarity; Con: Contribution, Cum: Cumulative)

\begin{tabular}{cccc|cccc}
\hline \multicolumn{3}{c|}{ Dary (Av.Si: 37.12\%) } & \multicolumn{4}{c}{ Rainy (Av.Si: 39.02\%) } \\
\hline Families & Av.Si & Con $(\%)$ & Cum $(\%)$ & Families & Av.Si & Con & Cum $(\%)$ \\
Linhomoeidae & 11.43 & 30.81 & 30.81 & Linhomoeidae & 12.25 & 31.39 & 31.39 \\
Xyalidae & 8.32 & 22.42 & 53.23 & Xyalidae & 11.75 & 30.11 & 61.49 \\
Axonolaimidae & 5.36 & 14.45 & 67.68 & Axonolaimidae & 6.83 & 17.51 & 79.01 \\
Chromadoridae & 5.12 & 13.8 & 81.48 & Chromadoridae & 4.16 & 10.66 & 89.67 \\
Comesomatidae & 1.76 & 4.74 & 86.22 & Neotonchidae & 1.28 & 3.29 & 92.95 \\
Desmodoridae & 1.26 & 3.39 & 89.61 & Oxystominidae & 0.89 & 2.28 & 95.23 \\
Cyatholaimidae & 0.98 & 2.64 & 92.24 & & & & \\
Neotonchidae & 0.90 & 2.43 & 94.67 & & & & \\
Oxystominidae & 0.63 & 1.70 & 95.37 & & & & \\
\hline
\end{tabular}

The average dissimilarity between dry and rainy season was fairly high with $64.06 \%$. Specifically, Linhomoeidae and Xyalidae were known as the two most contribution families, with $22.96 \%$ and $21.87 \%$, respectively. Families Axonolaimidae, Chromadoridae, and Neotonchidae were also responsible for those dissimilarities (ranged from 5.00\% to $13.13 \%$ ). The percentages of the remaining families were lower than $5.00 \%$ of the total contribution (Table 4). Results of an ANOSIM analysis also showed that there were significant differences in nematode communities' structure (family level) between dry and rainy season (Global $\mathrm{R}=0.072$, $\mathrm{p}$-value $=0.03$ ).

Tran et al. (2018) underlined that the environmental sediment in dry season of an organic shrimp ponds was separated from that ị rainy season. Salinity was a main environmental variable in the dry season, whereas in rainy season was governed by total nitrogen $(\mathrm{TN})$, total organic carbon (TOC), and dissolved oxygen (DO) [11].

Table 4. Average dissimilarities and major nematode families contributing to the dissimilarity between dry and rainy season. Cut off for low contributions: 95.00\% (Av.Dis: Average Dissimilarity; Con: Contribution; Cum: Cumulative)

\begin{tabular}{cccc}
\hline \multicolumn{4}{c}{ Average dissimilarity: 64.06\% } \\
\hline Families & Av.Dis & Con $(\%)$ & Cum $(\%)$ \\
Linhomoeidae & $(\%)$ & 22.96 & 22.96 \\
Xyalidae & 14.71 & 21.87 & 44.83 \\
\hline
\end{tabular}




\begin{tabular}{cccc}
\hline Axonolaimidae & 8.41 & 13.13 & 57.96 \\
Chromadoridae & 6.70 & 10.46 & 68.42 \\
Neotonchidae & 3.20 & 5.00 & 73.43 \\
Desmodoridae & 2.70 & 4.21 & 77.64 \\
Comesomatidae & 2.68 & 4.18 & 81.82 \\
Oxystominidae & 2.42 & 3.77 & 85.59 \\
Leptolaimidae & 1.79 & 2.79 & 88.38 \\
Cyatholaimidae & 1.78 & 2.77 & 91.16 \\
Sphaerolaimidae & 1.13 & 1.76 & 92.92 \\
Oncholaimidae & 0.56 & 0.88 & 93.80 \\
Selachinematidae & 0.56 & 0.88 & 94.68 \\
Monhysteridae & 0.55 & 0.85 & 95.53 \\
\hline
\end{tabular}

It is well known that the nematode community characteristics (density, diversity, distribution, and functional properties) can be affected by several abiotic/biotic variables such as salinity, temperature, organic matter and nitrogen, sediment grain size, oxygenation level, and food availability [17-20]. Therefore, the differences in sediment environmental characteristics between dry and rainy season are the reason for dissimilarity in the nematode communities structure. Nematodes with their rapid adaptation to changing environments can be used as a potential tool for bio-indicator. Changes in benthic faunal communities were generally detectable on high levels of taxonomic resolution such as family or order level [21]. However, in the present study, the sensitivity at the genus level resulted in higher sensitivity than at the family level. Indeed, the average dissimilarity in the genus level was higher than those in family level. Suggesting that the taxonomic rank of the genus can be considered as a good tool for environmental monitoring.

During the study period, three genera such as Terschellingia, Daptonema, and Parodontophora were the main genera contributing to similarity/dissimilarity between dry and rainy season. Genus Terschellingia is credited as indicators of pollution and organic enrichment conditions [22, 23]. Genus Daptonema is known to be tolerant to pollution and credited as an indicator of stressed conditions [24]. Moreover, genus Parodontophora is selected as indicators of a poor ecological quality status in the
Mediterranean coastal ecosystems because of its well-known tolerance to pollution [25]. Genera Terschellingia, Daptonema, Parodontophora, and their high densities may be indicative of the pressures in shrimp pond's sediment in both seasons. Although genus Terschellingia had contribution with a lower proportion than those in dry season but had also a high contribution in rainy season (with 30.61\%). Furthermore, genera Daptonema and Parodontophora were gaining their contribution increasing from dry to rainy season $(18.07 \%$ to $20.79 \%, 9.93$ to $11.72 \%$, dry to rainy season respectively). Perhaps the ecological quality status of sediment in dry season was better than those in rainy season.

\section{Conclusion}

Therefore, it can be concluded that the seasonality in the Tam Giang's organic shrimp farms ponds, Nam Can district, $\mathrm{Ca}$ Mau province strongly affected the nematode communities structure at genus and family level. Differences in sediment environmental characteristics between dry and rainy season are the reason for dissimilarity in the nematode communities structure. Nematodes with their rapid adaptation to changing environments can be used as a potential tool for bio-indicator.

\section{Acknowledgments}

The research was supported by the Institute of Tropical Biology (ITB), Vietnam Academy of Science and Technology (VAST). We thank the 
staff of the Department of Environmental Management and the Department of Biological Resources (ITB-VAST) for precious help with laboratory analyses. Furthermore, special thanks go to editors and anonymous referees for their constructive and critical reviews of our manuscript.

\section{References}

[1] F.Y. Lin, A.H. Vo, V.B. Phan, T.T. Nguyen, D. Bryla, C.T. Tran, J.B. Robbins, The epidemiology of typhoid fever in the Dong Thap Province, Mekong Delta region of Vietnam, The American journal of tropical medicine and hygiene 62 (5) (2000) 644-648. http://dx.doi.org/10.4269/ajtmh. 2000.62 .644 .

[2] F. Semprucci, M. Moreno, S. Sbrocca, M. Rocchi, G. Albertelli, M. Balsamo, The nematode assemblage as a tool for the assessment of marine ecological quality status: a case-study in the Central Adriatic Sea, Mediterranean Marine Science 14 (1) (2013) 48-57. http://dx.doi.org/10. 12681/mms.366.

[3] Q.X. Ngo, N.C. Nguyen, D.T. Nguyen, A. Vanreusel, Distribution pattern of free living nematode communities in the eight Mekong estuaries by seasonal factor, Journal of Vietnamese Environment. 4 (1) (2013) 28-33. https://doi.org/ 10.13141/jve.vol4.no1.pp28-33.

[4] C. Heip, M. Vincx, G. Vranken, The ecology of marine nematodes, Oceanography and Marine Biology: An Annual Review. 23 (1985) 399-489.

[5] M. Hodda, W.L. Nicholas, Nematode diversity and industrial pollution in the Hunter River Estuary, NSW, Australia, Marine Pollution Bulletin 17 (6) (1986) 251-255. https://doi.org/10.1016/0025-326X (86)90058-5.

[6] D.M. Alongi, Intertidal zonation and seasonality of meiobenthos in tropical mangrove estuaries, Marine Biology 95 (3) (1987) 447-458.

[7] C. Tudorancea, A. Zullini, Associations and distribution of benthic nematodes in the Ethiopian Rift Valley lakes, Hydrobiologia 179 (1) (1989) 81-96.

[8] M. Hodda, W.L. Nicholas, Production of meiofauna in an Australian estuary, Wetland 9 (2) (1990) 41-48. http://doi.org/10.31646/wa.200.

[9] S. Beier, W. Traunspurger, Seasonal distribution of free-living nematodes in the Körsch, a coarsegrained submountain carbonate stream in southwest Germany, Nematology 5 (4) (2003) 481504. https://doi.org/10.1163/156854103322683229.

[10] M. Hourston, I.C. Potter, R.M. Warwick, F.J. Valesini, K.R. Clarke, Spatial and seasonal variations in the ecological characteristics of the free-living nematode assemblages in a large microtidal estuary, Estuarine, Coastal and Shelf Science 82 (2) (2009) 309-322. https://doi.org/10. 1016/j.ecss.2009.01.018.

[11] T.T. Tran, T.L. Pham, T. Nguyen, X.Q. Ngo, Relationship of free-lingving nematode communities to some environmental characteristics in the organic shrimp farms, Ca Mau province, Vietnam Journal of Science and Technology 56 (5) (2018) 636-637. https://doi. org/10.15625/2525-2518/56/5/ 11864.

[12] T.T. Tran, T.M.Y. Nguyen, T. Nguyen, X.Q. Ngo, Meiofauna in the mangrove-shrimp farms ponds, Ca Mau province, Vietnam Journal of Science and Technology 55 (3) (2017) 271-284. https://doi. org/10.15625/2525-2518/55/3/8410.

[13] E.A. El Hag, Food and food selection of the Penaeid prawn Penaeus monodon (Fabricius), Hydrobiologia. 110 (1) (1984) 213-217.

[14] V.C. Chong, A. Sasekumar, Food and feeding habits of the white prawn Penaeus merguiensis, Marine Ecology Progress Series. 5 (2) (1981) 185-191.

[15] T.M.Y. Nguyen, T.T. Tran, T.D. Nguyen, X.Q. Ngo, Free living nematode communities as fundamental food for shrimps in the ecological model of mangrove - shrimp farming ponds, Nam Can district, Ca Mau province, Vietnam Journal of Biotechnology 16 (3) (2018) 581-588. https://doi. org/10.15625/1811-4989/16/3/1

[16] K.R. Clarke, R.N. Gorley, PRIMER v6: User Manual/Tutorial PRIMER-E, Plymouth, 2006.

[17] J. Ingels, A.V. Tchesunov, A. Vanreusel, Meiofauna in the Gollum Channels and the Whittard Canyon, Celtic Margin-how local environmental conditions shape nematode structure and function, PLoS One 6 (5) (2011). https://doi.org/10.1371/journal.pone.0020094.

[18] L. Cai, S. Fu, J. Yang, X. Zhou, Distribution of meiofaunal abundance in relation to environmental factors in Beibu Gulf, South China Sea, Acta Oceanologica Sinica 31 (6) (2012) 92-103. https://doi.org/10.1007/s13131-012-0256-2.

[19] X.Q. Ngo, N. Smol, A. Vanreusel, The meiofauna distribution in correlation with environmental characteristics in 5 Mekong estuaries, Vietnam, Cahiers de Biologie Marine 54 (1) (2013) 71-83. 
[20] B. Górska, K. Grzelak, L. Kotwicki, C. Hasemann, I. Schewe, T. Soltwedel, W. łodarska-Kowalczuk, Bathymetric variations in vertical distribution patterns of meiofauna in the surface sediments of the deep Arctic ocean (HAUSGARTEN, Fram strait), Deep Sea Research Part I: Oceanographic Research 91 (2014) 36-49. https://doi.org/ 10.1016/j.dsr.2014.05.010.

[21] M. Mueller, J. Pander, J. Geist, The effects of weirs on structural stream habitat and biological communities, Journal of Applied Ecology 48 (6) (2011) 1450-1461. https://doi.org/10.1111/j.13652664.2011.02035.x.

[22] M. Schratzberger, K. Warr, S.I. Rogers, Patterns of nematode populations in the southwestern North Sea and their link to other components of the benthic fauna, Journal of Sea Research 55 (2) (2006) 113-127. https://doi.org/10.1016/j.seares. 2005.07.002.
[23] M. Moreno, G. Albertelli, M. Fabiano, Nematode response to metal, PAHs and organic enrichment in tourist marinas of the mediterranean sea, Marine Pollution Bulletin 58(8) (2009) 1192-1201. https://doi.org/10.1016/j.marpolbul.2009.03.016.

[24] A.S. Alves, H. Adão, T.J. Ferrero, J.C. Marques, M.J. Costa, J. Patrício, Benthic meiofauna as indicator of ecological changes in estuarine ecosystems: the use of nematodes in ecological quality assessment, Ecological Indicators 24 (2013) 462-475. https://doi.org/10.1016/j.ecolind. 2012.07.013.

[25] M. Moreno, F. Semprucci, L. Vezzulli, M. Balsamo, M. Fabiano, G. Albertelli, The use of nematodes in assessing ecological quality status in the Mediterranean, Ecological Indicators 11 (2) (2011) 328-336. https://doi.org/10.1016/j.ecolind. 2010.05.011. 